\title{
Palate Fracture Profile in Plastic Reconstructive and Aesthetic Surgery of Soetomo Hospital : January 2012 - December 2017
}

Priscilla Valentin N. Agus Santoso Budi Lobredia Zarasade
Background: Palatal fractures are often associated with maxillofacial fractures and Le Fort fractures. The diagnosis and management of palatal fractures in the midface area is a challenge for a plastic surgeon in restoring function and aesthetics. With the results of this study, it is expected to be a database of maxillofacial fractures treated at SMF Reconstructive Plastic Surgery and Aesthetic Dr. Soetomo, Surabaya and gave the ability to make a fast and precise diagnosis for time and technical maxillofacial fractures.

Methods : This study uses medical record data for all patients diagnosed with palatal fractures in Dr. Soetomo General Hospital, Surabaya during January 2012 to December 2017. The variables studied were demographic data including sex, age, mechanism of occurrence of accidents, types of fractures, management, complications that occur and length of treatment.

Results : There were 82 patients with palatal fractures, with traffic accidents being the most common cause of palate fracture $(n=61)$ followed by workplace accidents and households in second place (12 and 9\%). Most sufferers were men $(68 \%)$, women $(14 \%)$ with the highest age range of men aged 19-30 years who were followed by ages 31-45. The most were parasagittal fractures (56\%), then Sagittal $(15 \%)$, paraalveolar (9\%), alveolar $(1 \%)$, comminutive $(1 \%)$. no fractures with anterior and posterolateral alveolar types, posterolateral type or transverse type fractures. Hospitalization period with plating (12 days), transmolar wiring (10.6 days), conservative (13.8 days).

Conclusions:

In this study assessed the experience in the reconstruction and aesthetic plastic surgery department of Dr. Soetomo General Hospital regarding palatal fractures and accompanying demographic data. The type of fracture that occurs is also related to the management performed. Incomplete medical records caused problems in this study.

Keyword: Palatal fracture, Maxillofacial fracture, Facial injuries, Maxillofacial injuries

$\mathrm{P}$ alatal fractures are often associated with maxillofacial fractures and Le Fort fractures. The diagnosis and management of palatal fractures in the midface area is a challenge for a plastic surgeon in restoring function and aesthetics. With the results of this study, it is expected to be a database of maxillofacial fractures treated at SMF Reconstructive Plastic Surgery and Aesthetic Dr. Soetomo, Surabaya and gave the ability to make a fast and precise diagnosis for time and technical maxillofacial fractures.

\section{Material \& Methods}

This study is a descriptive analytical study with a retrospective study design. Data was taken from medical records for all patients admitted to surgical inpatient and outpatient polyclinics and who were diagnosed with palatal fractures in Dr. Soetomo General Hospital, Surabaya during January 2012 to December 2017. Diagnostics were performed by radiological examination

Disclosure: The authors herely declare they have no financial interest in the information discussed in this article

using panoramic and Towne photos anteroposterior view. As with other 
management of maxillofacial fractures, definitive therapy should be carried out before 2 weeks. Conservative care is carried out if the fracture is stable without displacement. Conservative treatment is carried out with a non-chewing diet, analgesic administration, and with the installation of arch bars and maxillary mandibular fixation. ${ }^{1}$

Gender includes men and women. Age is divided into 4 groups, covering 1-18 years, 19-30 years, 31-45 years, and more than 46 years. The mechanism of the occurrence of accidents includes traffic accidents, violence and work accidents or household accidents. Duration of treatment compared to the treatment performed. Conservative management is to use the arch bar and rubber maxillomaxillary fixation. While the plating management is using plate and screw. The types of fractures studied were 6 types, including anterior and posterolateral alveolar, posterolateral, sagittal, parasagittal, comminutive and transverse. For the assessment of outcomes, the authors assessed the presence or absence of complaints from patients in the form of complications including the presence of malocclusion or not, and the presence or absence of pain.

\section{Results}

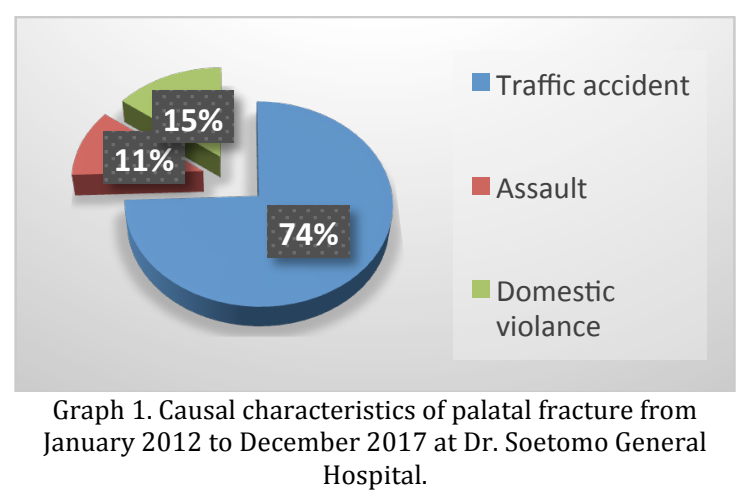

This graph shows that traffic accidents are the most common cause of palate fracture due to the lack of public awareness of driving compliance. On the other hand, workplace and household accidents are second, followed by violence, the majority of which are caused by criminal cases.

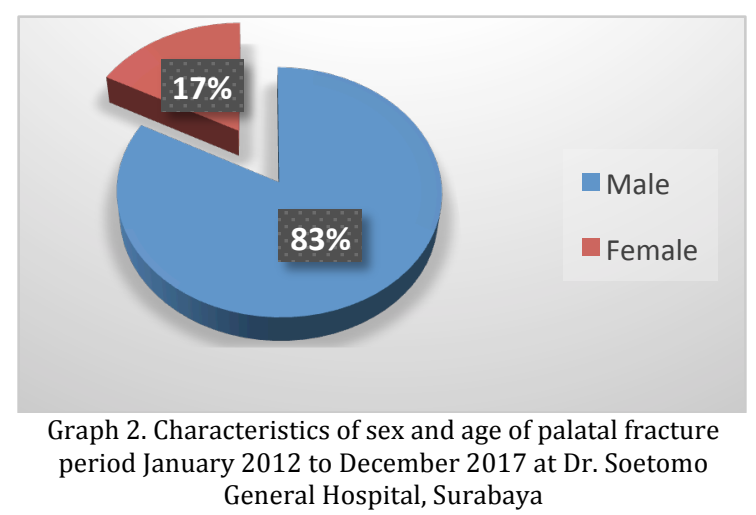

This graph shows that $82,9 \%$ were male and $17,07 \%$ were female.

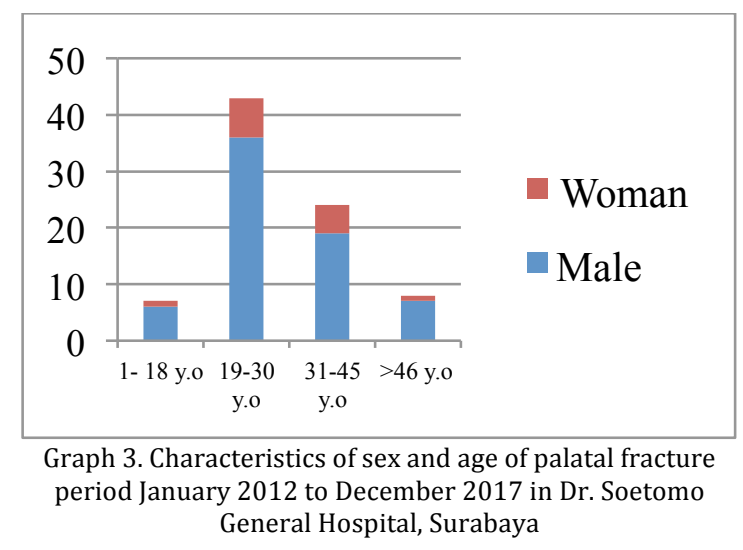

This graph shows that the majority of sufferers are men of productive age (ages 1930 years) due to high mobility in meeting economic and family needs.

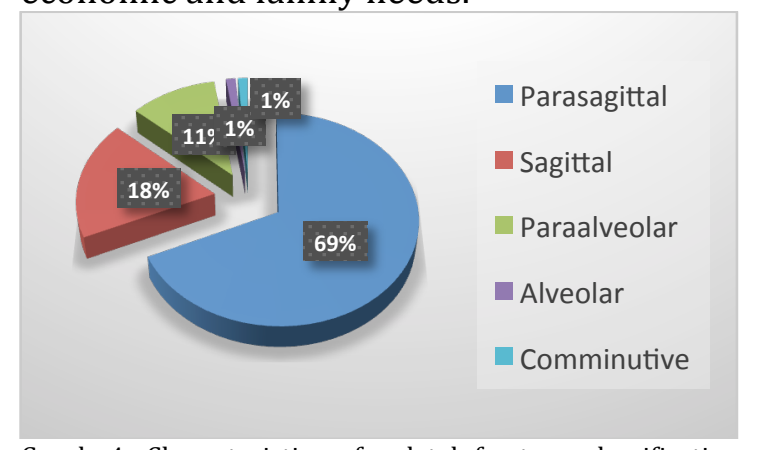

Graph 4. Characteristics of palatal fracture classification from January 2012 to December 2017 at Dr. Soetomo General Hospital, Surabaya.

In the case of SMF Reconstructive and Aesthetic Plastic Surgery Dr. Soetomo Hospital, Surabaya; no fractures with anterior 
and posterolateral alveolar types, posterolateral type or transverse type fractures.

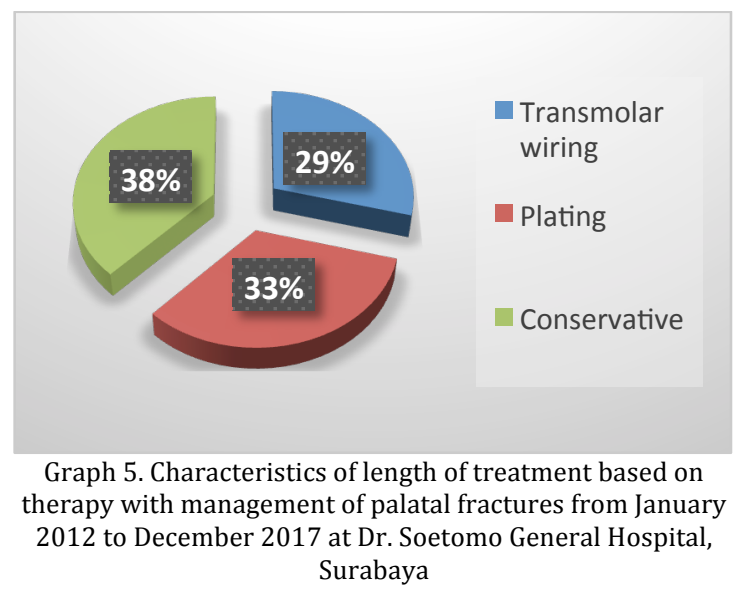

In patients with plating management, the hospitalization period reaches an average of 12 days, management with wiring reaches an average of 10.6 days and conservative therapy requires a longer time, which is 13.8 days. But this is because the fracture of the palate is always accompanied by other injuries, such as a head injury which makes the patient's care period longer. Usually also accompanied by cervical bone injury, fractures in the long bones and trauma of the internal organs.

\section{Discussion}

From the results of the retrospective study above, it was found that 82 cases of palatal fractures were treated by SMF Reconstructive and Aesthetic Plastic Surgery Dr. Soetomo General Hospital, Surabaya, where the highest number of patients was male, with an average age of $16-30$ years. The most common cause is a traffic accident and the most common type of palatal fracture is the parasagittal fracture type. The average hospital stay is 10.6 days in patients with transmolar wiring treatment, with plating is 12 days and patients with conservative management (mounting arch bar) are 13.8 days.
In a similar study in America, a total of 3147 patients were admitted to the Plastic Surgery and Reconstruction section of a university hospital in Newark, New Jersey in the period January 1, 2000 to December 31, 2012. There were 2738 male patients and 409 female patients with palatal fractures. , with a ratio of $87: 13$ and the average age is 35 years. The most common cause at this center is blunt trauma due to traffic accidents followed by violence and firearms. The majority of the areas affected by the fracture are alveolar palate fracture, followed by sagittal fractures.

Research at Chang gung memorial hospital, Taiwan; of 162 cases treated at SMF for Plastic and Reconstructive Surgery, there were 118 male and 44 female patients, with a ratio of 72.8: 27.2 with an average age of 24.5 years. The most common cause at this center is a motorcycle accident followed by violence. of the areas affected by the fracture, the majority are sagittal fractures. This is due to the high mobility and young age, and economic needs and demands to meet the family's economic needs. Histological development of midpalatal sutures begins in adolescence and synostosis occurs between the ages of 15 and 19.2,3 Sagittal fractures should occur mostly in children, because the strength of the palate bone synostosis in children is weaker than in adults. But in our study, cases of sagittal fracture were the majority in adults of the 4th decade. The low frequency of patients with sagittal fractures in our study was due to the high strength of synostosis with high bone stock in the midline area of the palate, where this also showed significant differences in the occurrence of sagittal fractures in adults. This is due to the large strength that causes fractures in areas with high bone stock. ${ }^{4}$

Research during the period of June 20, 2010 to December 20, 2013 in the city of Peshawar, Pakistan showed that of 65 cases of fracture of the palate, the patients were $85 \%$ with an average age of 45 years, and the most common type of fracture was sagittal fracture. $85 \%$ of patients were treated with 
intermaxillary wiring, $9 \%$ with ORIF plating, $6 \%$ with conservative (arch bar installation).

Of the 2 studies mentioned above, there were no significant differences regarding the causes of most palatal fractures, and the sex characteristics of patients. The most common type of fracture is parasagital due to the style and mode of injury from a traffic accident. Most patients are men because of high mobility at a young age, accompanied by more psychological factors that do not comply with driving rules and pressure from the social environment. Young age is also a factor that determines the number of accidents that occur today, due to emotions that tend to be unstable and do not think long. But what distinguishes the cause of palatal fracture in SMF Plastic and Reconstructive Surgery in Dr. Soetomo General Hospital, Surabaya is the absence of cases of firearms as a cause of fracture of the palate.

In the three cases above, the management of patients with plating and transmolar wiring requires more time for the treatment of patients in the hospital, because this trauma is always accompanied by panfacial fractures and severe head injuries. Evaluations conducted on postoperative patients from medical record data in outpatient installations showed no malocclusion, and 1 patient complained of pain until the third year postoperatively.

Park S designed an algorithm for palatal fracture management and provided a classification system based on care. The thing to note is the possibility of closed reduction, surgical management, the area for fixation, and the stability of the fracture segment itself. According to Park in the case of anterior fractures and minimal palate fractures, the use of an intermaxillary fixation (IMF) is sufficient. But if there is still an occlusion that has not been reached or a complaint of malocclusion in the postoperative period, then open reduction surgery must be performed.2

A similar approach was adopted in the current study. It was found that cases where palate fracture was associated with Le Fort II and in the symphysis fracture had a problem with achieving stable occlusion due to the rotation force. In the above cases, a similar approach was also considered to be carried out in cases with palatal fractures where the occlusions have not been achieved with the use of intermaxillary wiring alone. Usually this case occurs in a fracture that affects the mid face area.

The difficulties in this study were the limited accuracy of medical record data, and the loss of patient contact numbers and patients who did not regain control after surgery.

\section{Conclusion}

Palatal fractures are rare cases that arise as a result of midfacial or panfacial fractures caused by high energy trauma. In this retrospective study, we present details of the demographic data of patients with palate fractures in 1 trauma center at SMF Plastic and Reconstructive Surgery, Dr. Soetomo Hospital, Surabaya in the last 5 years. Most sufferers are young adult men aged 19-30 years, with the most causes of trauma being traffic accidents and the most common type of palatal fracture is parasagittal type.

The fracture of the palate itself is usually accompanied by other trauma, such as a head injury, long bone injuries, internal organ trauma that require a longer stay. Accurate diagnosis is needed with appropriate management in the management of palatal fracture cases. The results of our study showed fixation using transmolar wiring and plating, occlusion was achieved well, and obtained 1 of 82 patients with pain complaints from medical record data at the outpatient installation Dr. Soetomo Hospital, Surabaya.

\section{Reference}

1. 1. Trott, JA, Moore MH. Facial fractures. In: Craniomaxillofacial Trauma. David DJ, Simpson DA (editors). London: Pearson; 1995 
2. Persson M, Thilander B. Palatal suture closure in man from 15 to 35 years of age. Am J Orthod. 1977;72(1):42-52.

3. Melsen B. A histological study of the influence of sutural morphology and skeletal maturation on rapid palatal expansion in children. Trans Eur Orthod Soc. 1972:499507.

4. Sabherwal R, Irvine G, Sandy J. Orthodontic management of a Le Fort II and midline palatal fracture. $\mathrm{Br}$ Dent J. 2007;202(12):739-40

5. Allsop D. Skull and Facial Bne Trauma In: Nahum AM, Melvin J Accidental Injury: Biomechanics and Prevention. Berlin: Springer; 2002

6. Chen $\mathrm{CH}$, Wang TY, Tsay PK, Lai JB, Chen CT, Liao HT, Lin CH, Chen YR. A 162-case review of palatal fracture: management strategy from a 10-year experience. Plastic and Reconstructive Surgery: 2008 June; 121(6): 2065-2073.

doi: 10.1097/PRS.0b013e3181706edc

7. Cienfuegos R, Sierra E, Ortiz B, Fernandez G. Treatment of Palatal Fractures by Osteosynthesis with 2.0-mm Locking Plates as External Fixator. Craniomaxillofac Trauma Reconstr. 2010 Dec; 3(4): 223-230. doi: 10.1055/s-0030-1268519.

8. Cryer M H. The Internal Anatomy of the Face. Philadelphia: Lea \& Febiger; 1916.cde

9. Forrest C R, Phillips J H. Lower midface (Le Fort I) fractures. In: Prein J, editor. Manual of Internal Fixation in the Cranio-Facial Skeleton: Techniques Recommended by the Ao/Asif Maxillofacial Group. Berlin: SpringerVerlag; 1998.

10. Hendrickson M, Clark N, Manson P. Sagittal fractures of the maxilla: classification and treatment, Plast Reconstr Surg 101:319-332, 1998.

11. Hoppe IC, Halsey JN, Ciminello FS, Lee ES, Granick MS. A Single-Center Review of Palatal Fractures: Etiology, Patterns, Concomitant Injuries, and Management. Eplasty. 2017; 17: e20.

12. Le Fort R. Etude experimental sur les fractures de la machoire superieure, Parts I, II, III. Rev Chir Paris. 1901;23:208.

13. Melsen B. Palatal growth studied on human autopsy material: a histological, microradiographic study. Am J Orthod. 1975;68:42-54.

14. Park S, Ock JJ. A new classification of palatal fracture and an algorithim to establish treatment plan. Plast Recons Surg 2001; 107: 1669-76

15. Pollock R A. Buttressing and the Seven Buttresses. Chandler Medical Center,

University of Kentucky, Lexington, KY: 2006 Combined Craniomaxillofacial Trauma Services Conference; February 28.

16. Rimmel F, Marentette LJ. Injuries of the hard palate and horizontal buttress of the midface. Otolaryngol Head Neck Surg 1993; 109: 499505.

17. Thomas M V, Daniel T L, Kluemper T. Implant anchorage in orthodontic practice: the Straumann Orthosystem. Dent Clin North. 2006;50:425-437. 